\title{
El Renacimiento en la literatura vasca: Juan Pérez de Lazarraga
}

\author{
Iñaki ALDEKOA BEITIA \\ Euskal Herriko Unibertsitatea / Universidad del País Vasco (EHU/UPV) \\ Iñaki.aldekoa@ehu.es
}

\begin{abstract}
RESUMEN
Juan Pérez de Lazarraga es un poeta alavés del siglo XVI. Sabemos que murió en 1605 y que vivió en Madrid algún tiempo. Su poesía mezcla elementos de la poesía cancioneril y de la poesía renacentista, a la manera de Petrarca, influido por poetas del Renacimiento español. En este artículo se estudian algunos aspectos del manuscrito encontrado en 2004 que contiene numerosas poesías y una novela pastoril inconclusa.
\end{abstract}

Palabras clave: Juan Pérez de Lazarraga, manuscrito, Renacimiento, literatura vasca

[Recibido, enero 2011; aprobado, marzo 2011]

The Renaissance in Basque literature: Juan Pérez de Lazarraga

\begin{abstract}
Juan Perez de Lazarraga is a poet born in Alava in the sixteenth century. We know he died in 1605 and lived in Madrid for some time. His poetry combines elements of different kinds of poetry such as Renaissance, like Petrarch, influenced by the Spanish Renaissance poets. This article describes some aspects of the manuscript found in 2004 that contains numerous poems and an unfinished pastoral novel.
\end{abstract}

Keywords: Juan Pérez de Lazarraga, manuscript, Renaissance, Basque literature 


\section{Vida y obra}

Juan Pérez de Lazarraga es un poeta alavés del siglo XVI. No se conoce con exactitud la fecha de su nacimiento (1547-1548), pero sí la de su defunción (1605). Los Lazarraga procedían de Oñate, donde se ubica su casa solar, y sus descendientes, relacionados con los Garibay y los Guevara, pertenecían al linaje gamboino. Como tantas otras familias linajudas del país, los Lazarraga prestaron sus servicios a la Corona castellana; uno de sus antepasados inmediatos, Juan Pérez de Lazarraga, trabajó como secretario de los Reyes Católicos.

Algún poema del manuscrito deja entrever que nuestro poeta residió por algún tiempo en Madrid, probablemente no lejos del ambiente cortesano. Parece ser que el autor se encontraba en esta ciudad cuando su familia lo reclamó para casarlo. Corría el año de 1567. Casó con Catalina González de Langarica, mujer de buena familia, aunque, según el testamento publicado Gervario Di Cesare ${ }^{1}$, no sabía leer. El matrimonio tuvo dos hijos.

Además de poeta, Juan Pérez de Lazarraga fue genealogista e historiador. Escribió una Historia de Álava que no ha llegado hasta nosotros, y fue autor de una genealogía familiar minuciosamente estudiada por el documentalista donostiarra Borja Aguinagalde.

Cuando todavía nada se sabía acerca del manuscrito, Pérez de Lazarraga ya era conocido como "el poeta". Sus coplas y canciones nos traen el eco de acontecimientos que jalonaron su vida: el asesinato de su padre, la quema de Salvatierra o la celebración de torneos entre caballeros.

\section{El manuscrito de Pérez de Lazarraga}

Descubierto en 2004 por Borja Aguinagalde en Madrid, el manuscrito de Pérez de Lazarraga consta de 51 hojas y encierra en ellas una inconclusa novelita pastoril que ha llegado hasta nosotros mutilada, además de unas 60 poesías y canciones, 9 de las cuales fueron escritas en castellano. No parece probable que los textos fueran escritos con anterioridad a 1567.

Como era habitual en los manuscritos de aquel tiempo, tampoco al de Pérez de Lazarraga le faltó quien continuara la labor emprendida por él, haciendo nuevas aportaciones al manuscrito, de modo que parece adivinarse más de una mano en su confección ${ }^{2}$.

$\mathrm{Si}$ a esto le añadimos que en aquella época era normal la inclusión de poemas de otros autores sin especificar su procedencia o autoría (algo que hoy en día resultaría inadmisible), salta a la vista el grado de complejidad al que deberá someterse el estudioso de los manuscritos (siglos XVI y XVII) y el rigor que se

\footnotetext{
1 "El último legado de Juan Pérez de Lazarraga: su testamento", Sancho el Sabio, no 31, 2009, pp. 299-326.

${ }^{2}$ Véase J. Lakarra, G. Bilbao, B. Urgell, R. Gómez et al. (ed. ): "Lazarraga eskuizkribua: edizioa eta azterketa" (Vitoria, UPV/EHU, 2009), in http:/www.ehu.es/monumenta/Lazarraga/. Gracias a "Monumenta Linguae Vasconum" disponemos por primera vez de una transcripción segura de una buena parte de los textos del manuscrito. Las referencias de la obra de Lazarraga que se insertan en este artículo siguen las pautas de numeración propuestas por dichos investigadores.
} 
le exigirá. Valga de muestra un botón: en la colección de pliegos poéticos ${ }^{3}$ del Marqués de Morbecq, de la British Library, figura un poema que comienza con la glosa "El amor sin piedad/destruyó mi honestidad". "A la mia gran pena forte" ha sido un poema de múltiples desarrollos. De las tres glosas conocidas, una de ellas está recogida en el manuscrito de Pérez de Lazarraga.

Su copla VIII sigue a Gutierre de Cetina en la glosa que hace el sevillano de la canción "Zagala, cuán libre estás, / cuán soberbia, dura y fría, / pues yo espero que algún día / casarás y amansarás". Es clara la deuda contraída por Pérez de Lazarraga con respecto al poema de Cetina, o con respecto a alguna fuente anterior de la que abrevaron ambos. Más adelante volveremos sobre este tema.

El manuscrito también incluye tres poemas de Estibaliz Sasiola, poeta de la que nada se sabía hasta que su nombre apareció como autora de los poemas. Es obvio que alguien — ¿el propio autor?, ¿algún otro?- había insertado dichos poemas en el manuscrito. Claro está que por lo general se trataba de manuscritos que vivieron ajenos a cualquier interés de publicación.

Como se ha sugerido ya, todo ello dificulta el análisis y la crítica del documento. Tampoco se sabe nada acerca del grado de imbricación entre la novelita pastoril del inicio y los poemas que le siguen a modo de cancionero. Cuándo fue escrita la primera y cuándo los segundos. Quedan, pues, dudas que con el tiempo se irán esclareciendo. Este artículo trata de determinar la relación existente entre la literatura de Pérez de Lazarraga y la literatura española del Renacimiento. El objetivo fundamental que persigue es el de alumbrar la literatura del autor alavés a la luz de aquélla.

\subsection{Los manuscritos poéticos del siglo XVI}

En un estudio memorable, el maestro Rodríguez-Moñino ${ }^{4}$ trazó de manera magistral el modus operandi de los manuscritos poéticos y su raigambre en el siglo XVI español. Su estudio dejó meridianamente claro que no es posible conocer el estado de la poesía del Siglo de Oro obviando la vitalidad de los manuscritos u ocupándose exclusivamente de las obras impresas. Su tesis vendría a ser la siguiente: a tenor de las obras que conocemos en la actualidad, se podría conjeturar que la poesía áurea que han conocido los lectores del siglo XX y la que conocieron los contemporáneos del siglo XVI no tienen por qué coincidir: bien al contrario, pudiera ocurrir que poetas admirados y aplaudidos en su tiempo no hubieran llegado hasta nosotros sino a través de los manuscritos. O que nunca lo hicieran ${ }^{5}$.

\footnotetext{
${ }^{3}$ Antonio Rodríguez-Moñino, Los pliegos poéticos de la colección de la colección del Marqués de Morbecq (siglo XVI). Edición en facsímil precedido de un estudio bibliográfico. Madrid, Estudios bibliográficos, 1962.

${ }^{4}$ Antonio Rodríguez-Moñino, Construcción crítica y realidad histórica en la poesía española de los siglos XVI y XVII, Madrid, Castalia, 1968.

5 "Yo he sostenido siempre que entre muestro conocimiento de la poesía antigua y el que tenían los rigurosamente contemporáneos de ella hay una diferencia radical", in Antonio Rodríguez-
} 
Muchos poetas relevantes de la época murieron sin ver impresa su obra. Es el caso de Gutierre de Cetina, un poeta muy destacado para nosotros aunque su obra no llegara a publicarse hasta 1895 , trescientos años después de su muerte. Garcilaso de la Vega murió en 1536 y su obra se publicó en 1543; San Juan de la Cruz murió en 1591 y su obra se publicó en 1628, treinta y siete años después de su muerte; Fray Luis de León murió en 1591 y su poesía se publicó en 1631, cuarenta años después de su muerte.

Todo ello nos lleva a una reflexión que incluye los tres pilares sociológicos en los que se asienta la vida literaria del Siglo de Oro español: la transmisión, la periodización y los lectores. Fundamentalmente la recepción literaria se realiza de dos maneras: colectiva e individualmente. Los sermones y el teatro, junto a la lectura colectiva, donde una persona lee el libro y las demás escuchan, serían las formas en las que se concretaba la primera modalidad. La lectura individual de libros y manuscritos correspondería a la segunda. Como ya se ha apuntado, los libros impresos no dan cuenta de la vida literaria (y poética) del siglo XVI. Son mucho más numerosos los manuscritos que circulaban de mano en mano que los libros impresos disponibles. En este sentido, es ilustrativo el estudio que Fernando de Herrera dedicó a la obra poética de Garcilaso de la Vega. En él se puede apreciar cómo el autor hace referencia a poetas que fueron conocidos en el siglo XVI pero que en absoluto lo son en la actualidad. ¿Cómo los llegó a conocer entonces? Indudablemente, a través de dichos pliegos sueltos y de los cuadernos o manuscritos que circulaban de mano en mano.

No es otra cosa lo que sucede en la poesía vasca con el poeta Arnaud Oihenart y su L'Art Poétique basque (1665) ${ }^{6}$, tratado de poética que no llegó a publicarse hasta 1967, en el que el autor hace referencia a una serie de poetas (Salgize, Jean de Etchegaray Armando de Logras) cuyas obras no han llegado hasta nosotros. Obviamente, al tratarse de soportes más ligeros, el peligro de extravío o pérdida que los pliegos poéticos o los manuscritos comportaban era muy superior.

He aquí el poema (A8) que glosaba Cetina y que supuestamente constituye el modelo que siguió Pérez de Lazarraga para escribir el suyo:

Zagala, quán libre estás, quán sobervia, dura y fría;

pues yo 'spero que algún día

casarás y amansarás.

De no tener subjeción

ni de amor ni de marido,

tienes tan endurecido

el rebelde coraçón.

Moñino, Poesía y cancioneros (siglo XVI), RAE, Madrid, 1968, p. 78. Aunque en los últimos años se ha avanzado muchísimo, las palabras de Rodríguez-Moñino siguen teniendo vigencia.

${ }^{6}$ Arnaud Oihenart, L'Art poétique basque (1665), ed. P. Laffitte GH, 1967. 
Pero sienpre no estarás tan libre de fantasía:

[e \} spero en Dios que algún día casarás y amansarás.

Si el miedo de ser amada de libre nada te aprieta, bien es que prueves subjeta si es más grave el de casada. En fin, al yugo vendrás, y entonces, señora mía, dirás: "Ay del que dezía casarás y amansarás!"”.

Las yras, las asperezas, desdenes, desabrimientos, novedades, movimientos, los desgustos y estrañezas, mientras que libre serás, usa dellos todavía; que yo espero que algún día casarás y amansarás.

Allí me veré vengado, y tú quedarás pagada; yo, de verte malcazada, tu de averme mal tratado. Allí, traidora, dirás, llorando de noche y día: "Triste de aquel que dezía casarás y amansaras".

Pero ¿cómo se explica que Pérez de Lazarraga conociera la poesía de Cetina ya en el siglo XVI si esta no se imprimió hasta finales del siglo XIX? José Manuel Blecua nos informa de que este poema de Cetina no fue descubierto hasta 1954 en la Biblioteca Provincial de Toledo, tras permanecer en uno de sus códices durante cuatro largos siglos durmiendo el sueño de los justos ${ }^{7}$. La glosa de Cetina figuraba en un cancionero colectivo inédito. Entonces, ¿tenía Pérez de Lazarraga conocimiento de dicho cancionero, o lo tomó copiado de alguna otra fuente o manuscrito?

\footnotetext{
${ }^{7}$ Véase José Manuel Blecua, Sobre poesía de la Edad De Oro, Gredos, Madrid, 1970. Labrador, J. J. \& Di Franco, R., \& Montero J. (ed. ) Cancionero sevillano de Toledo, Sevilla, Universidad de Sevilla, 2006, pp. 154-156.
} 
Todo ello nos conduce a pensar que, aunque la obra poética de Cetina no fue publicada hasta finales del siglo XIX, los poetas del siglo XVI llegaron a tener conocimiento de muchas de sus creaciones, que habrían circulado en manuscritos o cartapacios de poesías varias.

El siglo XVI fue testigo del ascenso de la poesía lírica al puesto que la posteridad le otorgaría. La conquista de dicho privilegio en el parnaso literario no acontece con anterioridad al siglo áureo. Todavía en el siglo XVI la temática religiosa y la didáctico-moral gozaban de una relevancia considerable, y no les iba a la zaga un género como la epopeya. Quizás la figura de Petrarca ilustre de modo adecuado la evolución que con el paso del tiempo experimentarían los distintos géneros poéticos en el favor y gusto del público. Frente a las expectativas que el humanista depositó en su poema África, su Canzoniere irrumpió imparable, irradiando lo mejor de la poesía occidental posterior. Acaso para Pérez de Pérez de Lazarraga, las coplas y canciones que reunió en su manuscrito no fueran sino "divertimento compañero de la música y las fiestas, propio de la mocedad" al lado de proyectos que el autor estimaba de mayor enjundia, como La Historia de Álava o la genealogía familiar, que lo mantuvieron ocupado a lo largo de su vida y en los que invirtió su dedicación y su saber.

¿Pero qué tipo de literatura nos ofrece el manuscrito de Pérez de Lazarraga? Nuestro autor se prodiga en la novela pastoril, que gozó de una enorme popularidad a partir del éxito de la Diana de Jorge de Montemayor, y en la poesía de estilo cancioneril, tan hermanada con la vida cortesana. Siguiendo el modelo establecido por sus precursores, Pérez de Lazarraga combina la prosa y la poesía en la primera, y amalgama coplas y canciones de amor en la segunda.

\section{De la novela de caballerías a la novela pastoril}

En el período álgido de la novela de caballerías, el oficio de pastor no era precisamente el mejor ponderado; al contrario, si lo comparamos con la tradición aristocrática de la caballería, tenía una baja consideración. Sin embargo, las cosas empezarían a cambiar a partir de 1560 . Sin cuestionar la preeminencia de la que gozó la novela de caballerías hasta el siglo XVII, conviene subrayar que su pujanza había comenzado ya a declinar a partir de 1560. Frente a las Historias de la Literatura que insisten en que el Quijote de Cervantes vino a rematar y clausurar dicha tradición, $M$. Chevalier preferirá tomarle el pulso al género en los años previos a su publicación, para concluir que hacia 1600 la tradición de la novela de caballerías estaba ya sentenciada ${ }^{9}$. No obstante, se trataba de un género que había gozado de enorme éxito entre los siglos XII y XVI. El ciclo bretón del rey Arturo y sus caballeros de la Mesa Redonda venía deleitando la fantasía de los lectores de la Edad Media desde el siglo XII hasta el Amadís de Gaula, bien entrado el Renacimiento, cuyo repertorio de héroes, imágenes e historias

\footnotetext{
${ }^{8}$ Rafael Lapesa, De la Edad Media a nuestros días, Madrid, Gredos, 1971, p. 146.

${ }^{9}$ Véase Maxime Chevalier, Lecturas y lectores en la España del siglo XVI y XVII, ed. Turner, Madrid, 1976, pp. 87-89.
} 
cautivaron a media Europa. Muchos de los nombres de los héroes de estas novelas tomarían vida en el repertorio de los nombres de la época, como Tristán, Floristán o Perceval (así se denominaba uno de los protagonistas del cantar de gesta "La quema de Mondragón").

Para cuando Pérez de Lazarraga había empezado a escribir su novela pastoril, se había iniciado el declive de la novela de caballerías. El ardor guerrero venía a atemperarse ante la sentimentalidad de la tradición pastoril: menos luchas y más quejas de amor. En adelante, el héroe de la caballería amansará a favor del pastor, que heredará muchas de las características de aquél y no se mostrará tan aguerrido e irascible como en tiempos pasados, sino más sentimental y sensible al amor. Es evidente que asistimos a un cambio de sensibilidad que viene a coincidir con el auge de la novela pastoril, que se produce en torno a 1560. En este clima espiritual se fragua el éxito de La Diana de Montemayor y se apuntala el éxito del género.

En este sentido, conviene subrayar que es la propia tradición caballeresca basta comparar el primer Amadís con sus prolongaciones en manos de Feliciano de Silva- la que manifiesta dicha transformación.

Cabría preguntarse por el motivo que nos lleva a insistir tanto en las novelas de caballerías, no siendo éste precisamente el género prioritario de Pérez de Lazarraga. La razón estriba en que éste perteneció a la aristocracia linajuda del país, siendo dicha nobleza, junto a curas y religiosos, la que concentraba un buen número de lectores del género ${ }^{10}$. Su obra poética ofrece numerosos ejemplos de su afición al mundo de la caballería. Uno de sus primeros poemas revive episodios caballerescos cuyas reminiscencias perdurarían aún en el siglo XVI: me refiero a las justas medievales. Bajo una escenificación cuidadosamente preparada para la ocasión, los torneos entre caballeros rememoran la aureola de la caballería en su manifestación más pura. Esos poemas (A1) rezuman el esplendor del pasado, a la manera de los Amadís y otros héroes de la caballería populares para los lectores del siglo XVI.
"[...] doncellas flor de lis, muchas,
todas vestidas de rojo:
- Protegidas habitamos
el castillo de Gebara, estas nuestras prendas rojas
las cosimos con contento, mil caballeros en justas se retan por nuestra causa..."

En este punto cabe recordar el legado que el imaginario medieval transfirió al Renacimiento, un pasado que todavía resultaba cercano. Encontramos un

\footnotetext{
10 "De la aristocracia procederán sin ninguna duda buena parte de los lectores de las obras de entretenimiento", M. Chevalier, op. cit., p. 27.
} 
ejemplo ilustrativo de esta presencia de lo medieval en las incontables justas que se celebraban con motivo de alguna conmemoración. Así ocurrió en 1517 con motivo del traslado de la Corte a Valladolid. Asimismo, entre 1517 y 1544 se celebraron justas entre caballeros por motivos tomados de las novelas de caballerías, y en 1527, con motivo del nacimiento de Felipe II, se celebraron torneos organizados a la manera de Amadís de Gaula.

Algo más tarde, en 1566, con motivo de la llegada de Isabel de Valois, se celebran en Bayona justas entre caballeros, en las que participa lo más granado de la aristocracia del país. En ellas se escenifican aventuras en el más puro estilo novelesco. No faltarán encantamientos y otras maravillas de sabor medieval: el caballero libera a una dama virgen de las garras de un gigante, etc. En 1569 se celebró en Vitoria un torneo de similares características ${ }^{11}$.

A pesar de que todas estas escenificaciones del pasado resulten extrañas para nuestra sensibilidad histórica, los contemporáneos vieron en ellas "una imagen sublimada de la sociedad aristocrática en que vivían" ". Semejantes representaciones revivían el pasado aristocrático de los antepasados, un pasado que seguía vivo en las celebraciones festivas del siglo XVI, así como en la ficción y la poesía de Juan Pérez de Lazarraga.

Nos referimos a un pasado glorioso en el que la vieja aristocracia pudo campar a sus anchas. Pero el esplendor se había extinguido ya. A lo sumo, perduraba su nostalgia o su evanescente aureola. Para entonces, la vieja nobleza levantisca, derrotada y subordinada por el poder real, se había visto reducida a desempeñar un papel compensatorio en el juego de las armas, o el de comparsa en la vida mundana y lúdica de la corte. Ésta se convertiría en una oportunidad inmejorable de hacer carrera sin desafiar la autoridad de la monarquía absoluta. Muchos jóvenes de la nobleza abandonarían sus aisladas casas-torre y se trasladarían a Madrid, Valladolid o Toledo, seducidos por las nuevas expectativas que se les ofrecía en la vida cortesana. Tampoco en esto fue una excepción Pérez de Lazarraga.

Este período histórico de inflexión en el que se encuentra inmersa la mentalidad nobiliaria coincide en lo literario con un claro decantamiento a favor de la novela pastoril; al cambio producido en la relación entre el estamento nobiliario y el poder real le sigue un cambio de sensibilidad que afecta al gusto de los lectores. En definitiva, las heroicidades de Amadís poco se avenían con el nuevo modo de vida de la corte, de mayor relumbre y refinamiento, a la par que

\footnotetext{
${ }^{11}$ En dicho torneo, junto a otros veintidós caballeros, tomó parte un tal Juan de Larrea (Larrea es el pueblo donde nació y vivió nuestro poeta). No se sabe con certeza la relación que había entre ambos personajes o si realmente se trataba de nuestro poeta de Larrea, Juan Pérez de Lazarraga. Sea como fuere, el anagrama que el susodicho caballero llevaba inscrito en su escudo rezaba así: "El fuego en que veis que ardo / me sostiene / porque amor así lo quiere". El mismo representa una lengua de fuego en la que se consume el caballero, mientras una dama le observa. Véase Eulogio Serdán Aguirregaviria, Historia de Vitoria, Sendoa, Oyarzun, 1985.

12 Maxime Chevalier, op. cit., pp. 98-103.
} 
menos belicosa y más dada a ensoñaciones idealistas. Aunque la estela del pasado siguiera iluminando aún el presente del autor (B18):

\author{
Un buen día yo venía \\ por un estrecho camino, \\ en una mano traía \\ rodela de puro acero \\ cabalgando buen caballo, \\ en la otra mano traía \\ una lanza bien adornada, \\ buena adarga en el arzón, \\ un fuerte arnés en el cuerpo, \\ con corazas y con casco, \\ Tomando, como a menudo, la tristeza \\ por única compañía, \\ y como guía la ventura, \\ mi aspecto lucía \\ francamente penoso. \\ De tal manera llevaba \\ este corazón tan triste \\ que, sin pensar en las cosas \\ que habría de ver más tarde, \\ me confundí de camino.
}

Estas estrofas vendrían a confirmar lo dicho hasta el momento. ¿Pero qué sentimiento embarga a Joan Pérez de Lazarraga? (Con este nombre se presenta en el poema el sujeto poético). En efecto, se trataría de una autoficción recreada al modo novelesco de las caballerías. Cuando han cambiado drásticamente las condiciones de vida de la vieja aristocracia nobiliaria, lo que queda es el recurso de la ficción. No faltará en Pérez de Lazarraga este tipo de juego novelesco, atemperado, eso sí, por la sensibilidad bucólica y pastoril de la nueva sentimentalidad. Porque, indefectiblemente, cuanto más cortesana (y urbana) es su sensibilidad, más bucólico y arcádico resulta su gusto literario. Me refiero a la arcadia de las novelas pastoriles, imaginario que se vivió desde las cortes urbanas. No es casualidad que este nuevo gusto literario coincidiera en el tiempo con una obra de enorme éxito como la de Fray Antonio de Guevara, Menosprecio de corte y alabanza de aldea, o con el triunfo definitivo del tópico horaciano "Beatus ille”. El poeta-guerrero se había convertido en poeta-pastor. 
Algunos años después, ya en el siglo XVII, Cervantes ${ }^{13}$ retomaba en Coloquio de los perros la cuestión pastoril y concluía de este modo: "Las novelas pastoriles son casos soñados y bien escritos para entretenimiento de los ociosos y no verdad alguna." Para finales de la segunda década del siglo XVII, había pasado ya la moda de la novela pastoril. ${ }^{14}$

Jorge de Montemayor publicó en 1559 su famosa Diana, obteniendo inmediatamente un éxito apoteósico entre los lectores. El camino emprendido por la Diana contó con numerosos seguidores. A partir de 1563 (el autor había muerto en 1561), Alonso Pérez y Gil Polo se postularon como continuadores de su obra. El primero lo hizo con La segunda parte de la Diana (1564), y Gil Polo fue un digno competidor de su antecesor con la Diana enamorada (1564). A pesar de la distinta factura y calidad de sus obras - la segunda sería reconocida y aplaudida como una digna competidora de su antecesora-, a ninguna de las dos le faltó el favor del público. No olvidemos que incluso Cervantes creó su Galatea (1585), una de sus primeras obras sólidas, siguiendo la senda exitosa de la Diana.

\subsection{La novela pastoril de Pérez de Lazarraga}

La novelita pastoril de Pérez de Lazarraga sigue la estela de Los siete libros de la Diana (La Diana) (1559), de Jorge de Montemayor, que alcanzó una inmensa popularidad en las principales literaturas europeas del momento (Francia, Italia e Inglaterra) y fue profusamente imitada. El manuscrito de Pérez de Lazarraga constata el auge del género $\mathrm{y}$, además, se convierte en el primer texto en prosa de la literatura vasca del que se tiene constancia.

El género pastoril funde la corriente caballeresca con la tradición bucólica, que procede, sobre todo, de Virgilio. Como indica J. B. Avalle-Arce15, "la canonización literaria de Virgilio en los siglos medios contribuyó a la fijación y perduración del tipo pastoril". Si al ciclo litúrgico de la Navidad, que aparece ya en las primeras obras dramáticas del Medievo, le sumamos la aportación del virgilianismo bucólico, "se comienza a ovillar la popularidad simpar de la literatura bucólica en el Renacimiento". El primer gran éxito corresponde a La arcadia, del italiano Jacopo Sannazaro, y el segundo, a la corriente petrarquista, que cristaliza en Garcilaso de la Vega, cuyas Églogas, junto con los amores de los pastores Salicio y Nemoroso, constituyen la culminación poética de la tradición bucólica-pastoril.

La obra de Sannazaro significó un importante antecedente genérico, marcando ya algunos de los recursos, temas, motivos y tópicos que llegarían a la La Diana de Montemayor, y, por derivación, a la estirpe de sus imitadores (Pérez

\footnotetext{
${ }^{13}$ Miguel de Cervantes, "Coloquio de los perros", in Novelas ejemplares (1613), Castalia, Madrid, 1982, p. 284.

${ }_{14}^{14}$ Juan Bautista Avalle-Arce, La novela pastoril española, Istmo, Madrid, 1975.

15 Juan Bautista Avalle-Arce, "Estudio Preliminar", in La Diana, Jorge de Montemayor, Barcelona, Crítica, 1996, p. X.
} 
de Lazarraga fue uno de ellos), tales como la alternancia entre la prosa y el verso o el motivo del viaje como elemento catalizador de la trama. El acierto de Montemayor radica en haber remozado su obra de una sentimentalidad abstracta, idealizada y atemporal, de clara tradición neoplatónica, destinada a un público de caballeros y damas de la corte que "gustó de disfrazarse de pastor en sus ratos de esparcimiento". La verdad es que algunos episodios de la novelita de Pérez de Lazarraga no carecen de efectismo dramático; me refiero concretamente a los desmayos en cadena que acontecen en la fuente, lugar ameno con connotaciones eróticas en torno al cual se reúnen los cuatro protagonistas de la narración.

Los protagonistas de los devaneos amorosos de la narración de Pérez de Lazarraga responden, con ligeras variaciones, a los nombres de su modelo. Así, entre música de pastores, Sirena (Sireno), Silverio (Silvano), Silvia y Dorido, los personajes de la obra, nos conducen por valles y florestas, fuentes umbrías y riberas del Duero, y con ellos asistimos a apariciones sobrenaturales de estirpe caballeresca a lo Amadís o Clarián, de cuya última referencia se hace eco el texto a través del pastor que lleva su nombre. A medida que nos acercamos al final de la narración, tal y como ha llegado a nuestras manos, los protagonistas serán sometidos a un rito de paso del gusto de las ficciones caballerescas: mediante la intervención fantástica de un consejero del dios Marte que les suministra un espejo mágico, todos ellos superarán la prueba y saldrán bien parados del trance novelesco. Se supone que la novela continúa o, cuando menos, admite la adición de más episodios y nuevos lamentos de amor.

Los personajes son cautivos del mal de amores, contra el que poco o nada pueden hacer la voluntad humana y la medicina (Pérez de Lazarraga no introdujo brebajes mágicos como remedio, recurso habitual en las novelas pastoriles y caballerescas) $^{16}$. El amor, obra del destino ciego, caprichoso e infantil que infunde Cupido, ennoblece, no obstante, al amante, cuya queja se reviste de un halo de espiritualidad. Visto en perspectiva, sorprende que semejantes devaneos suscitaran tanto aplauso. Nos encontramos ante una moda. Del mismo modo que, fieles a la tradición caballeresca que provenía de la Edad Media, se celebraban justas en el siglo XVI, no menos entusiasta fue la moda pastoril de la que se contagió la corte. Parece altamente probable que Pérez de Lazarraga conociera La Diana de Montemayor, de la cual seguramente extrajo más de una enseñanza.

Tampoco conviene olvidar la devoción que mostró el Renacimiento respecto a la fábula de Píramo y Tisbe. El éxito de esta fábula, junto a la de Hero y Leandro, pertenecientes ambas a Las metamorfosis de Ovidio, fue inmenso. Son numerosos los autores del Renacimiento que se valen de dichas fábulas: Jorge de Montemayor, Antonio de Villegas, Cristóbal de Castillejo, Gutierre de Ceti-

\footnotetext{
${ }^{16}$ Cervantes no era amigo de tales trucos: “...soy de parecer que no se queme, sino que se le quite todo aquello que trata de la sabia Felicia y de la agua encantada", in Don Quijote de la Mancha, vol I. Edición empleada: Juventud, Barcelona, 1974, p. 73 (ed. de Martín de Riquer).
} 
na, Miguel de Cervantes. Y también Pérez de Lazarraga. He aquí algunas de las estrofas de la fábula que insertó en el poema A11 de su manuscrito:

“(...) Vivían cada uno en su casa, pero eran casas contiguas;

mientras fueron jóvenes

acostumbraban los dos a andar

sin compañía alguna, mas

desde entonces siempre juntos.

Como todos se admiraban

en grandísima manera

de ver cómo Martín y Flora

iban siempre los dos solos,

los padres de Flora

la han encerrado,

porque enseguida tuvieron

más de una mala sospecha.

Cuando los enamorados

así prisioneros se vieron,

sus corazones estaban

muy tristes en dondequiera.

Como de sus pensamientos

el dolor era sustento, un remedio se buscaron, que pagaron a alto precio.

Para poder verse uno al otro

la medianera horadaron, y se han puesto un mirador que ambos tienen muy a mano."

Para finalizar este apartado, conviene mencionar la afición que embargó al Renacimiento hacia la literatura morisca. En la edición de La Diana de 1561, edición que bien pudiera haber sido rastreada por Pérez de Lazarraga, se incorpora una historia morisca, "El Abencerraje y la hermosa Jarifa", además de otras obras como el "Triunfo de Amor" de Petrarca y "La historia de Píramo y Tisbe". Uno de los protagonistas de "El Abencejarre y la hermosa Jarifa" es Narváez, cuyo nombre figura en la novela pastoril de Pérez de Lazarraga transmutado en salvaje malvado (la aparición de salvajes era común en la tradición pastoril). 


\section{La poesía cancioneril de Pérez de Lazarraga}

Como se puede observar, el texto del autor alavés, además de responder "a la boga de lo pastoril como representación lúdica del mundo cortesano"17, reúne los motivos, la casuística y la retórica amatoria que configuran su poesía de estilo cancioneril. No faltarán en ésta la galantería de tono cortesano, las delicadas maneras ni el resto del ceremonial del amor cortés, donde el gentil galán queda conturbado y cautivo de la belleza de su dama, a quien pondera por su belleza, virtud y discreción y a la que se apresta a servir mientras le suplica que le conceda el galardón. En fin, todo el ritual del amor cortés, en el que se invierten los valores medievales y donde el caballero y el poeta se vuelven siervos de la dama, depositaria de la nobleza y respetabilidad que se le tributaba al señor feudal. He aquí un ejemplo de semejante ritual en Pérez de Lazarraga (A7):

-Tienes un gran poderío, don del Señor de los Cielos; en cuanto veo tus ojos, allí prendido me quedo.

En alto aprecio, como mereces, tengo estos pensamientos, y mientras viva ni un punto habré de menospreciarlos.

La nobleza y la espiritualidad de la dama son algunos de los atributos que la adornan:

-Miedo me das, querida, sin palabras me dejas.

Más claro te lo diría, ay, si tuviera licencia.

Cuanto más corto en palabras se muestra el caballero, mayor es la hondura de los sentimientos que le embargan. Todo homenaje a la belleza de la dama comportaba un tributo de amor, bien fuera real o fingido. En el caso de nuestro poeta, el segundo predomina claramente sobre el primero. Asimismo, conviene precisar que, como ocurrió preferentemente en la lírica trovadoresca, los requerimientos de amor de las poesías de Pérez de Lazarraga iban dirigidas a las doncellas. La poesía amatoria que escribió no es, presumiblemente, sino decorativo juego cortesano y juvenil. Como dice R. Lapesa (1971: 146): "La poesía era, en aspectos esenciales, un divertimento compañero de la música y las fiestas, propio de la mocedad".

${ }^{17}$ Juan Montero, "Prólogo", in Jorge de Montemayor, La Diana, op. cit., p. XLVII. 
Es necesario advertir que la lírica cancioneril del siglo XV y principios del XVI se concibió para ser cantada, no solo recitada y leída, lo cual no implica que siempre tuviera que serlo.

Son numerosos los motivos y préstamos que toma Pérez de Lazarraga de la tradición de la poesía cancioneril de sabor medieval: Flordelisa (Flor de lis); la leyenda de Macías, mártir de amor y ejemplo de amadores; la referencia a Pantasilea, reina de las amazonas, popularizada en las versiones medievales de la leyenda troyana; el elogio del rey, de su señor, de una ciudad o de un reino, o, como hace Pérez de Lazarraga, de su tierra. En el Siglo de Oro confluyen la tradición continuadora del arte procedente de los cancioneros y la poesía italianizante, petrarquista y clásica. Conviene recalcar, no obstante, el creciente interés que fue mostrando el siglo XVI hacia géneros populares y de estirpe medieval como el villancico y el romancero. En este rico panorama de tendencias convergen la poesía culta y estilizada, acrisolada en los sonetos de Petrarca, y la poesía de tradición popular. ${ }^{18}$

La poesía de Pérez de Lazarraga nunca emprendió la senda italianizante de Cetina, Boscán o Garcilaso. Su poesía no conoció la espiritualidad de un Ausias March. Su copla VIII sigue a Gutierre de Cetina en la glosa que hace el sevillano de la canción "Zagala, cuán libre estás, / cuán soberbia, dura y fría, / pues yo espero que algún día / casarás y amansarás". Sin embargo, no debemos olvidar que "casarás y amansarás" responde a un proverbio popular del siglo XVI. He ahí una buena muestra de la manera en que los poetas cultos de la época (entre ellos Pérez de Lazarraga) se servían del acervo tradicional. No será otra la estrategia que sigue el escritor vasco respecto a motivos que aparecerán con frecuencia en numerosos cancioneros: el motivo de "La bella malmaridada"19 o el de "La malmonjada".

Pérez de Lazarraga cultivó, pues, una poesía que no fue fecundada por la nueva espiritualidad artística que dominó la poesía más excelsa del siglo XVI. Su poesía es de molde más tradicional, aunque intercale en alguna ocasión imágenes de sabor clásico como el de Cupido, el carro del triunfo o la diosa Fortuna. En este sentido, nuestro autor queda a medio camino incluso de Oihenart, poeta vasco del siglo XVII, en quien el influjo italianizante, desprovisto ya del neoplatonismo que dominó el Renacimiento desde los tiempos de Petrarca, se

\footnotetext{
${ }^{18}$ Véase Rafael Lapesa, "Poesía de cancionero y poesía italianizante", in Garcilaso. Estudios Completos, Madrid, Bella Bellatrix (Istmo), 1985, pp. 213-238.

${ }_{19}$ Véase José J. Labrador Herranz \& Ralph. A. Di Franco, 2001, "Continuidad de la poesía del XV en cancioneros del XVI”, in J. L. Serrano Reyes \& J. Fernández Jiménez (ed.), Juan Alfonso de Baena y su cancionero. Actas del I Congreso Internacional sobre el Cancionero de Baena (Baena, del 16 al 20 de febrero de 1999), Baena, Ayuntamiento de Baena, pp. 201-213.

${ }^{20}$ Siguiendo la numeración establecida por el equipo de investigación "Monumenta Linguae Vasconum", el poema B17 reúne algunos motivos que encuadran en el tópico de la "Malmonjada". El poema se hace eco del motivo de Juan Rodríguez Padrón, que reza así: "Aunque me vedes assí / cautivo, libre nascí". Véase B. Dutton \& V. Roncero, La poesía cancioneril del siglo XV, Madrid, Iberoamérica, 2004, p. 312.
} 
ha trocado en un refinadísimo artefacto poético. La poesía de Oihenart, aunque despojada de su contenido espiritual, sigue conservando la conciencia artística del buen orfebre en el pulimiento de sus versos, alcanzando así un alto grado de estilización. Si es platónica la idea que anima la poesía del dolce stil novo, donde la dama obra en quien la mira una purificación y mejora moral, en manos de Petrarca "equivale a componer pulidos versos que ganan la inmortalidad de la fama para el poeta y para la amada". ${ }^{21}$ La poesía de Pérez de Lazarraga se encuentra muy lejos del escrutinio sutil de los afectos del alma que aporta la poesía del italiano.

Cuando Pérez de Lazarraga rinde tributo a la belleza femenina, no sigue la pauta de la poesía petrarquista del Renacimiento, a la que el poeta de Arezzo infundió su impronta en lo tocante a la descripción de las características físicas de la dama. La poesía cortesana de estilo tradicional no se demora en la descripción de sus rasgos físicos. En cambio, Petrarca y Oihenart sí se extienden en la descripción de los rasgos esenciales de la dama, idealizando su figura y su porte: ojos azules, cabellera blonda, dentadura de perla, cuello esbelto, etc.

La exposición de las querellas amorosas de Pérez de Lazarraga transcurre en absoluta despreocupación respecto a la naturaleza circundante, rasgo que delata su procedencia tradicional. No son menos antiguas las constantes invocaciones a Dios que aparecen en su poesía. En la canción y copla VIII, nos encontramos ante una poesía de circunstancia que, después de algunas digresiones sobre el amor, acaba glosando una de las fábulas que más cautivó al mundo medieval y al renacentista (Antonio de Villegas, Jorge de Montemayor, Cristóbal de Castillejo, Luis de Góngora, etc.): la de Píramo y Tisbe. No se encontrarán en la poesía de Pérez de Lazarraga enrevesadas referencias mitológicas, devotas o eruditas.

Si algo confirma la poesía amorosa del poeta alavés es su enorme desapego de cualquier atisbo de espiritualidad que pudiera contener el repertorio convencional del amor cortés. Aunque mucho más refinado que Bernard Dechepare, primer autor de la literatura vasca, autor del Linguae Vasconum Primitiae (1545), Pérez de Lazarraga deja bien sentado el carácter de su cortesía; la imprecación que dirige a Amor porque la doncella contraviene alguno de sus mandamientos no deja lugar a la duda: el poeta exige que castigue a la belle dame sans merci que no se aviene a su deseo de conquista. En este sentido, algunos poemas son definitivos $^{22}$ (A16, A17). La poesía A21 se burla de la convención

\footnotetext{
${ }^{21}$ M. R. Lida de Malkiel, Estudios sobre la literatura española del siglo XV, Madrid, José Porrúa, 1977, p. 262.

${ }^{22}$ El motivo del conjuro estaba muy difundido en los cancioneros. Baste recordar el de Francisco Coatana (Cancionero General II, Madrid, 2004, pp. 43-51), poema que lleva como epígrafe la siguiente advertencia: "Y esta primera es unos Conjuros de Amor, que hizo a su amiga, conjurándola con todas las fuerças del amor" [...] "Aquella fuerça gigante / con que Amor derriba y cansa / el animal / que viene humilde delante / la donzella que le amansa..." (referido al unicornio); "Aquel llanto que publica / con su llanto de amargura / desmedido / la viuda tortolica / cuando llora con tristura / su marido / y se busca soledad..." (tortolica); "Aquel amor tan derecho / y
} 
de la cortesía y satisface su deseo de manera más efectiva, propia de la poesía más popular y menos elevada. Otra de las características que definen el sentido de su poesía es la que delata su familiaridad con la poesía popular y erótica (de erotismo subido) que fluía en los cancioneros más plebeyos. Las poesías A19 y A21 se recrean en imágenes y tópicos sexuales — lancetas y emplastos- que corrían fuera de los cancioneros oficiales; probablemente ni siquiera el tono del villancico "Perutxo y Anton" (A13), aunque vertido a lo divino por un siglo $\mathrm{XVI}$ religioso, procediera de fuentes tan veneradas. Me refiero al villancico cuya primera estrofa reza así: "Buenas nuevas buena / Perucho y Anton, / Que hoy es nacida / Nuestra salvación.,"23

Es evidente el grado de refinamiento que muestra la poesía de Pérez de Lazarraga si la comparamos con la de Dechepare. Éste apenas se resiente del radiante influjo que ejercen las diversas corrientes innovadoras de tradición provenzal y cortés que se funden a partir del siglo XIV con las tendencias poéticas que iluminan el Renacimiento italianizante y dominan el siglo XVI europeo. Todas estas corrientes influyen en los escritos de Pérez de Lazarraga, pero, si lo comparamos esta vez con Oihenart (el humanista y poeta culto del siglo XVII), se observará la distancia que media entre ellos. En efecto, Pérez de Lazarraga queda a medio camino entre el mundo de la poesía cancioneril del siglo XV y comienzos del XVI, lastrada de muchos elementos propios de la hidalguía palaciega en declive y la implantación plena del modelo petrarquizante, que dará sus frutos más maduros en poetas como Herrera en la poesía castellana, Ronsard en la francesa y Oihenart en la vasca.

\section{Referencias bibliográficas}

AAVV, Lazarraga eskuizkribua: edizioa eta azterketa (Vitoria, UPV / EHU, 2010). Dirección electrónica en Internet: www.ehu.es/monumenta/lazarraga.

ALDEKOA, Iñaki, Historia de la literatura vasca, San Sebastián, Erein, 2004.

ALín, José María, El cancionero español de tipo tradicional, Madrid, Castalia, 1991.

AVAlle-ARCE, Juan Bautista, La novela pastoril española, Istmo, Madrid, 1975.

, "Estudio preliminar", La Diana, Jorge de Montemayor, Barcelona, Crítica, 1996 ,

BLECUA, José Manuel, Sobre poesía de la Edad de Oro, Gredos, Madrid, 1970.

querencias tan estrañas / del ave que rompe el pecho / y da a comer sus entrañas / por amor..." (pelícano). Según avanza el conjuro, el amante despreciado lanza la siguiente admonición: “.../ por que crea tu passión / y ante mí hagas pedaços / a ti mismma, / ...que, al cabo ya de tu muerte, / pidiéndome compassión, / des el alma”. Tanto el conjuro como el bestiario que lo adorna se encontrará en la poesía de Lazarraga.

${ }^{23}$ Véase Francisco de Ocaña, Cancionero para cantar la noche de Navidad y las fiestas de Pascua (Juan de Gracián, Alcalá, 1603). Véase también P. Alzieu, R. Jammes, I. Lissorgues, Poesía erótica del Siglo de Oro, Crítica, Barcelona, 2000. 
Cátedra, Pedro M., Nobleza y lectura en tiempos de Felipe II. La biblioteca de don Alonso Osorio, Marqués de Astorga. Valladolid, Junta de Castilla y León, 2003.

CheVAlier, Maxime, Lectura y lectores en la España de los siglos XVI y XVII, Madrid, Turner, 1976.

CORREAS, Gonzalo, Vocabulario de refranes y frases proverviales, ed. Louis Combet, revisada por Robert Jammes y Maite Mir-Andreu, Madrid, Castalia, 2000.

Cossío, José María de, Fábulas mitológicas en España, Madrid, Espasa-Calpe, 1952.

Di CeSARE, G.; "El último legado de Juan Pérez de Lazarraga: su testamento", Vitoria, Sancho el Sabio 31, 2009.

DUTTON, B. \& RONCERO, V., La poesía cancioneril del siglo XV, Madrid, Iberoamérica, 2004.

GARTZIA, Prudentzio, Lazarraga. Ernazimentua euskaraz, Pamplona, Pamiela 2005.

LABRADOR, J. J. \& DiFranco, R., \& Montero J. (ed. ) Cancionero sevillano de Toledo, Sevilla, Universidad de Sevilla, 2006.

LAKARRA, Joseba Andoni, "Juan Perez Lazarragakoren eskuizkribua (XVI. mendea): lehen hurbilketa", http://www.gipuzkoaeuskara.net/albisteak/1077905633, 2004.

LANDA, Iñigo, Lazarragaren eskuizkribua-Transkripzioa, http://klasikoak.armiarma.com/lazarraga/ .

LAPESA, Rafael, De la Edad Media a nuestros días, Madrid, Gredos, 1971. , "Poesía de cancionero y poesía italianizante", in Garcilaso: Estudios Completos, Madrid, Bella Bellatrix (Istmo), 1985.

MonTERO, Juan, "Prólogo", La Diana, Jorge de Montemayor, 1996, XLVII.

-,"Sobre imprenta y poesía a mediados del XVI (con nuevos datos sobre la princeps de Las obras de Jorge de Montemayor)", Bulletin Hispanique, 1, 2004, 81-102

RODRÍGUEZ-MOÑINO, Antonio, Construcción crítica y realidad histórica en la poesía española de los siglos XVI y XVII, Madrid, Castalia, 1968.

—, Poesía y cancioneros (siglo XVI), Madrid, RAE, 1968.

SALABERRI MUÑOA, Patxi, "Lazarragaren artzain-nobela irakurtzen", Egan 56: $3 / 4$..

URKIzU, Patrizio, "Joan Pérez de Lazarraga, autor de Dianea / Koplak (Madrid, 1567), primer novelista y poeta vasco", Madrid, UNED, Revista de Lengua y literatura catalana, gallega y vasca, 2004.

, Joan Perez de Lazarraga. Dianea \& Koplak. Madrid 1567, San Sebastián, Erein, 2004. 